\title{
PENGARUH KONFIGURASI LIQUID JET FLOW KOLOM GELEMBUNG TERHADAP KEMAMPUAN ABSORPSI GAS KARBONDIOKSIDA
}

\author{
Setiadi*, Dijan Supramono, Sukirno, dan Nur Istiqomah \\ Departemen Teknik Kimia, Fakultas Teknik, Universitas Indonesia \\ Kampus Baru UI Depok 16434 \\ Email: setiadi@che.ui.ac.id
}

\begin{abstract}
Abstrak
Upaya meningkatkan kinerja absorpsi gas $\mathrm{CO}_{2}$ yang memanfaatkan kolom gelembung dan liquid jet flow telah banyak dilakukan. Keunggulan kolom gelembung dalam riset ini adalah kolom menyebabkan gas entrainment (pengisapan gas) dan dispersi gas ke dalam cairan yang membentuk awan gelembung. Pemilihan konfigurasi liquid jet flow terbaik berdasarkan posisi nosel dan arah sudut tembakannya dan dengan mengukur rasio laju volumetrik aliran gas entrainment terhadap laju volumetrik aliran cairan $\left(\mathrm{Q}_{\mathrm{G}} / \mathrm{Q}_{\mathrm{L}}\right)$ serta gas hold-up untuk setiap konfigurasi. Konfigurasi terbaik digunakan untuk menentukan kinerja kolom gelembung untuk mendapatkan kinerja kemampuan absorpsi yang setinggi-tingginya. Uji absorpsi dilakukan terhadap konfigurasi terbaik dengan menggunakan absorben larutan $\mathrm{NaOH}$ dengan laju alir $5 \mathrm{~L} /$ min pada tekanan atmosferik dan umpan gas $\mathrm{CO}_{2}$ dengan kadar 96,6\%. Hasil penelitian menunjukkan bahwa konfigurasi memberikan pengaruh cukup signifikan dan bahwa konfigurasi terbaik memberikan gas hold-up kisaran 0,55-0,65 dan rasio $Q_{G} / Q_{L}$ bernilai 1,3-1,8. Uji absorpsi menunjukkan berkurangnya kadar $\mathrm{CO}_{2}$ menjadi 0,01\% hingga $0,07 \%$ setelah absorpsi kurang dari 5 menit dan tetap tidak berubah sampai 10 menit. Hal ini menandakan bahwa absorpsi terjadi secara kimiawi antara gas $\mathrm{CO}_{2}$ dan $\mathrm{NaOH}$ and tidak terjadi desorpsi walaupun kolom gelembung tetap resirkulasi. Populasi gelembung menunjukkan distribusi ukuran gelembung lebih dominan pada rentang diameter antara 0,00097-0,00184 $\mathrm{mm}$.
\end{abstract}

Kata Kunci: Konfigurasi liquid jet, kolom gelembung, gas entrainment, absorpsi gas $\mathrm{CO}_{2}$

\begin{abstract}
Efforts to improve the performance of $\mathrm{CO}_{2}$ absorption using bubbling columns and liquid jet flow have consistently been developed. The advantage of the present column is the presence of gas entrainment by suction of nozzle and the gas dispersed throughout the bulk of liquid by the formation of bubble clouds. The selection of liquid jet flow configuration used parameters of nozzle position and liquid jet inclination. The configurations have been examined by hydrodynamic test by measuring the ratio of volumetric rate of gas to that of liquid exiting nozzle $\left(\mathrm{Q}_{\mathrm{G}} / \mathrm{Q}_{\mathrm{L}}\right)$ and gas holdup. Absorption test to the best configuration used $\mathrm{NaOH}$ solution with flowrate of 5 litres/min at atmospheric pressure and $\mathrm{CO}_{2}$ gas feed of $96.6 \%$. The results showed that the configurations of liquid jet flow gave significant effect on hydrodynamics and that the best configurations had gas hold-up in the range of $0.55-0.6$ and $\mathrm{Q}_{\mathrm{G}} / \mathrm{Q}_{\mathrm{L}}$ 1.3-1.8. Absorption tests showed that $\mathrm{CO}_{2}$ concentration can be reduced into $0.01 \%$ $0.07 \%$ in less than five minutes and the absorption should proceed with the chemical reaction up to 10 minutes with no indication of $\mathrm{CO}_{2}$ desorption. The bubbles were generated in the column predominantly in the diameter range of $0.00097-0.00184 \mathrm{~mm}$.
\end{abstract}

Keywords: Configurations of liquid jet, bubble column, gas entrainment, $\mathrm{CO}_{2}$ gas absorption

*korespondensi 


\section{Pendahuluan}

Gas $\mathrm{CO}_{2}$ merupakan salah satu gas penyebab efek rumah kaca pada lapisan atmosfir bumi, yang diduga kuat bisa menimbulkan efek global warming. Untuk mencegah semakin meluasnya efek tersebut, emisi gas $\mathrm{CO}_{2}$ harus dikurangi. Salah satu cara untuk mengurangi emisi gas $\mathrm{CO}_{2}$ adalah dengan proses absorpsi dimana gas dikontakkan dengan cairan yang mampu melarutkan gas tersebut. Kolom gelembung pancaran (jet bubble column) merupakan salah satu alat kontak antara fasa gas dan cair yang berfungsi sebagai media perpindahan massa fasa gas ke dalam fasa cair. Di industriindustri seperti industri kimia dan petrokimia, kolom gelembung pancaran telah secara luas digunakan dan difungsikan sebagai reaktor kimia. Kolom gelembung pancaran juga penting dalam bidang proses aerasi natural, pengolahan mineral, pengolahan air limbah, proses fermentasi dan flotasi serta sistem industri, termasuk di dalamnya pabrik kimia (Rabindran, 2001).

Keuntungan kolom gelembung pancaran diantaranya adalah sederhana dalam perancangan, mudah dalam pengoperasian dan pemeliharaan alatnya, volume reaktor yang dibutuhkan kecil, ukuran diameter gelembung yang terdispersi ke dalam cairan kecil, luas area spesifik antarfasa yang besar serta dapat memperoleh koefisien perpindahan massa yang sangat besar dibanding kolom gelembung konvensional lainnya (Ide dkk., 2001). Selain itu, pencampuran yang terjadi antara fasa gas-cair diperoleh sendiri dari gerakan tumbukan cairan yang mengenai cairan stagnan dalam kolom, gas akan terhisap dan terdispersi ke dalam cairan lebih sempurna. Tumbukan tersebut juga akan membentuk pusaran eddy sehingga tidak diperlukan lagi alat pengaduk (Liu dan Evans, 1998).

Dibandingkan dengan alat kontak gascair lain berbentuk tubular/venturi, kolom gelembung pancaran memiliki nilai koefisien perpindahan massa yang tinggi namun perbedaan di antara keduanya tidak terlalu signifikan. Namun dari segi energi yang hilang per satuan volume, kolom gelembung pancaran memiliki keunggulan yang cukup signifikan dibanding venturi (Lee dan Tsui, 1998). Ditambah lagi, jika dibandingkan dengan reaktor packed column dan sieve tray, pada kolom gelembung cairan tidak terdapat masalah dalam hal penurunan tekanan, persen flooding, foaming, loading maupun channeling.

Permasalahan yang timbul adalah apabila awan gelembung yang terbentuk di dalam cairan menjadi media stagnan yang dikenai tumbukan liquid jet, maka tumbukan tersebut sudah tidak efektif untuk bisa menimbulkan awan gelembung lagi karena semakin sulit terbentuknya lubang terompet yang berfungsi sebagai perangkap gas. Serta cairan arus pusaran eddy sudah menjadi aliran 2 fasa gas-cair, sehingga momentum tumbukannya juga berkurang. Arus pusaran eddy tersebut sangat berpengaruh terhadap pembentukan awan gelembung (Yamagiwa dan Kusabiraki, 1990).

Penelitian yang mengungkap secara detail tentang pengaruh konfigurasi terhadap kemampuan absorpsi masih langka. Pada tahun 2000, Akira dkk. telah mengamati korelasi antara kedalaman penetrasi gelembung terhadap efek geometri nosel. Namun, hal tersebut hanya dilakukan pada vertical liquid jet dengan posisi nosel dengan hanya beberapa sudut di atas permukaan cairan atau tidak tercelup.

Pada dasarnya semakin banyak awan gelembung yang dihasilkan maka semakin efektif perpindahan massa $\mathrm{CO}_{2}$ ke dalam fasa cair, sehingga absorpsi berlangsung jauh lebih efektif. Oleh karenanya, penelitian ini bermaksud melakukan pengamatan tentang pengaruh konfigurasi liquid jet flow terhadap kemampuan absorpsi gas $\mathrm{CO}_{2}$ dengan mempertinggi awan gelembung yang terbentuk di dalam cairan. Yang dimaksudkan dengan konfigurasi dalam penelitian ini adalah variasi posisi nosel, dalam hal ini berupa sudut dan kedalaman nosel tercelup yang melepaskan liquid jet ke dalam cairan dalam kolom gelembung pancaran.

Sedangkan kemampuan absorpsi $\mathrm{CO}_{2}$ ditentukan oleh jumlah gas yang terhisap (gas entrainment $=Q$ ), hold-up gas $\left(\varepsilon_{g}\right)$ dan distribusi gelembung. Penelitian ini bermaksud untuk mengukur besaran parameter-parameter tersebut dalam berbagai kondisi setiap konfigurasi jet flow. Berdasar parameter tersebut, penelitian ini bertujuan untuk memperoleh konfigurasi liquid jet flow dalam sistem kontak antara fasa gas dan cair (hold-up fasa gas dan gas entrainment) yang optimal.

\section{Dasar Teori}

Fenomena dasar dari prinsip konfigurasi untuk kontak gas-cair yang 
didesain ini adalah berdasarkan terbentuknya terompet permukaan stagnan yang diakibatkan oleh tumbukan liquid jet berkecepatan tinggi dengan cairan yang stagnan seperti diilutrasikan pada Gambar 1). Tumbukan tersebut mengakibatkan gas akan terhisap dan terperangkap lubang terompet dan terbentuk lapisan film gas diantara cekungan terompet dan liquid jet. Diperkirakan terbentuknya awan gelembung gas terjadi akibat lapisan film gas mengalami pemecahan akibat tumbukan arus pusaran eddy yang timbul dari pusaran cairan yang menumbuk downcomer (Evans, 1990).

Laju gas yang terhisap dipengaruhi oleh kedalaman penetrasi gelembung dari pancaran jatuh cairan. Kedalaman penetrasi gelembung memiliki korelasi terhadap efek geometri nosel (Akira dkk., 1990).

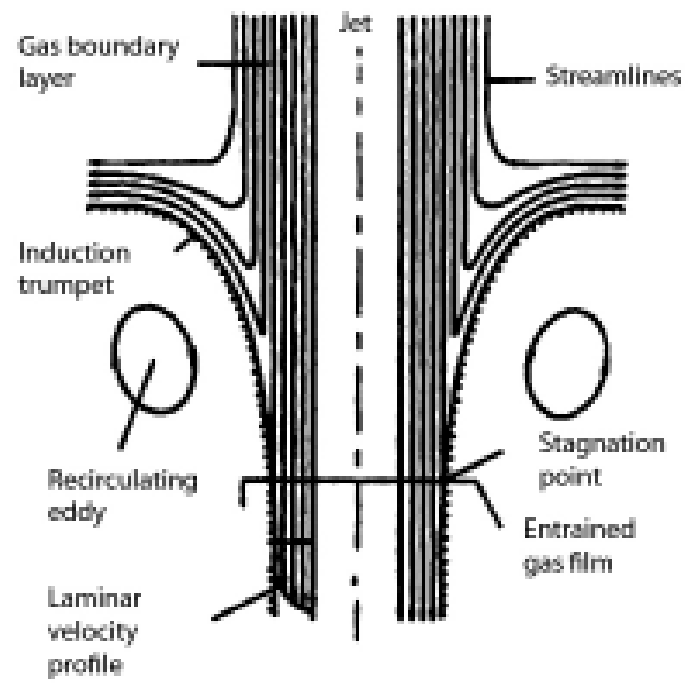

Gambar 1. Ilustrasi fenomena tumbukan jet pada permukaan cairan yang stagnan (Evans, 1990).

Terdapat tiga daerah hidrodinamika pada jet bubble column seperti terihat pada Gambar 2 yaitu daerah pancaran bebas (free jet zone), daerah pancaran jatuh (plunging jet zone) dan daerah aliran dua fasa yang seragam (uniform two-phase flow jet). Lubang cairan yang berbentuk seperti terompet terjadi di daerah pancaran bebas dan daerah pancaran jatuh yang mengakibatkan gas akan terhisap ke dalam kolom gelembung. Pada kedua daerah tersebut akan terjadi pusaran eddy (eddy current). Sedangkan pada daerah aliran dua fasa yang seragam, fasa gas akan terdispersi merata ke dalam fasa cair (Evans, 1990)

Berdasarkan sifat alirannya, pada umumnya terdapat tiga jenis aliran fluida yaitu laminar, transisi dan turbulen. Pada aliran laminar, fluida mengalir tenang tanpa diiringi oleh pusaran (vortek) meskipun terdapat gangguan di sepanjang aliran fluida. Sebaliknya pada aliran turbulen, aliran fluida bersifat chaos (terlihat tak beraturan) yang dicirikan dengan keberadaan pusaranpusaran fluida. Kondisi transisi merupakan daerah peralihan antara laminar dan turbulen dan merupakan wilayah aliran yang tidak stabil sehingga sering digambarkan sebagai garis putus-putus dalam diagram alir fluida.

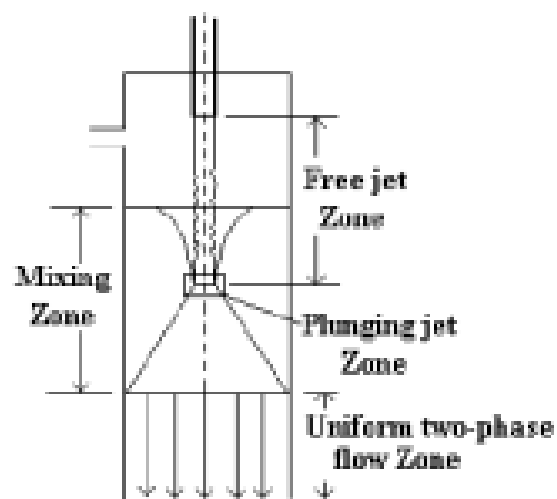

Gambar 2. Definisi daerah hidrodinamik kolom gelembung pancaran (Evans, 1990).

\section{Metodologi}

Gas $\mathrm{CO}_{2}$ dari tabung dialirkan menuju kolom flat yang berisi cairan absorben $\mathrm{NaOH}$ 0,01 M dengan laju alir sebesar $5 \mathrm{~L} /$ menit dan kadar 96,6 \%. Penempatan nosel diposisikan dengan sudut yang ditentukan dengan menggunakan foto kamera. Cairan dimasukkan ke kolom flat hingga mencapai nosel tercelup sampai kedalaman yang diinginkan. Pengukuran laju alir volumetrik cairan $\left(\mathrm{Q}_{\mathrm{L}}\right)$ diketahui dari meteran air, tekanan cairan diketahui dari pressure indicator dan laju alir gas diketahui dari perbedaan ketinggian dalam manometer $\mathrm{CCl}_{4}$ yang telah dikalibrasi dengan menggunakan bubble soap flowmeter. Cairan dipancarkan oleh kepala nosel ke dalam kolom flat sehingga gas akan terhisap melalui lubang yang terdapat pada bagian samping kepala nosel. Lean gas akan keluar dari bagian atas kolom flat. Sedangkan cairan akan keluar lewat bagian bawah kolom dan diresirkulasi menuju pompa. Untuk uji hidrodinamika, digunakan air dan udara. Kemudian pada sejumlah konfigurasi terpilih dilakukan uji absorpsi $\mathrm{CO}_{2}$ dengan menggunakan absorben $\mathrm{NaOH}$ dan gas $\mathrm{CO}_{2}$. Saat uji operasi, diambil sampel gas $\mathrm{CO}_{2}$ sebelum dan sesudah masuk ke kolom flat. 
Sampel tersebut kemudian dianalisa dengan alat Gas Chromatography. Prosedur di atas pun diulangi kembali.

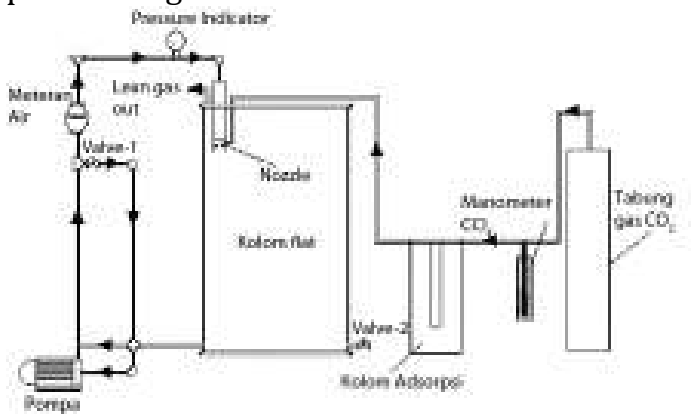

Gambar 3. Skema rangkaian peralatan

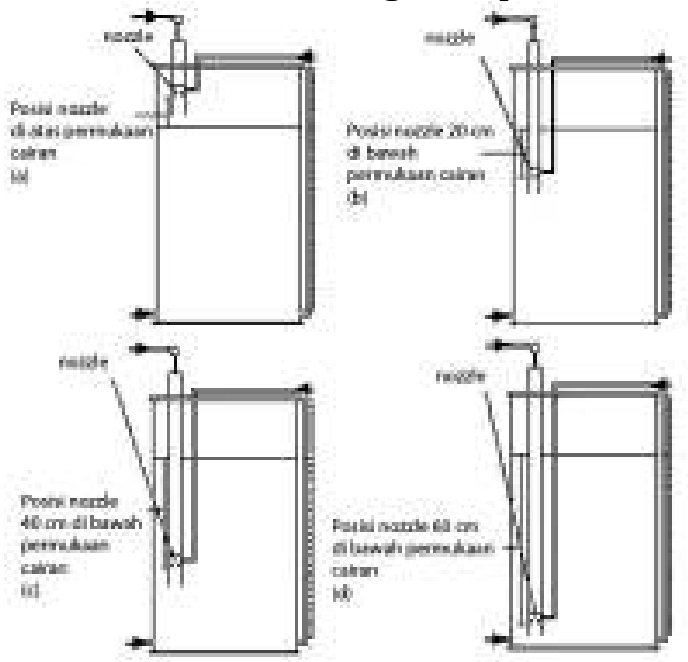

Gambar 4. Berbagai sketsa posisi nosel terhadap permukaan cairan.

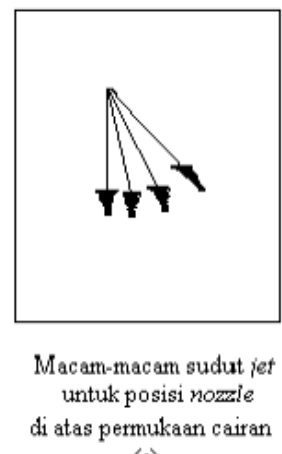

(a)

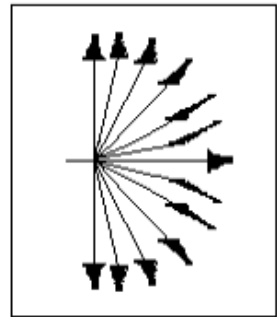

Macam-macam sudut jet untuk posisi nozzle (b) di bawah permukaan cairan

\section{Gambar 5. Berbagai sketsa sudut nosel}

Konfigurasi liquid jet flow didefinisikan sebagai sudut dan posisi nosel dari permukaan cairan di kolom flat. Sketsa konfigurasi liquid jet flow seperti terlihat pada Gambar 4. Penempatan nosel bisa dalam posisi tercelup maupun tidak tercelup tercelup. Nosel yang tidak tercelup berada di atas permukaan cairan (Gambar 4a), sedangkan nosel yang tercelup berada di

dalam cairan pada kolom flat dengan kedalaman yang divariasikan antara $0-60 \mathrm{~cm}$ (Gambar 4 b-d). Untuk nosel yang tidak tercelup, hanya beberapa sudut yang dapat dilakukan yakni $0-90^{\circ}$ sudut tembakan (Gambar 5 a). Sedangkan untuk nosel yang tercelup (Gambar 5 b), lebih banyak variasi sudut yang dapat dilakukan walaupun untuk kedalaman nosel tercelup yang cukup dalam $(\sim 60 \mathrm{~cm})$. Dari variasi posisi nosel tersebut didapatkan ada 82 jenis variasi konfigurasi jet flow.

Pengukuran sudut dan kedalaman untuk masing-masing konfigurasi diilustrasikan pada Gambar 6. Pengukuran sudut tumbukan liquid jet berdasarkan arah horisontal berlawanan dengan arah jarum jam. Pengukuran tersebut dilakukan dengan pengambilan data foto seluruh konfigurasi sebelum eksperimen dioperasikan. Posisi sudut tembakan jet bernilai positif antara 0 90 derajat (di atas garis horisontal) dan bernilai negatif bila sudut tembakkannya dengan arah dibawah horizonatal. Sedangkan posisi kedalaman nosel diukur dari permukaan cairan sampai dengan posisi nosel.

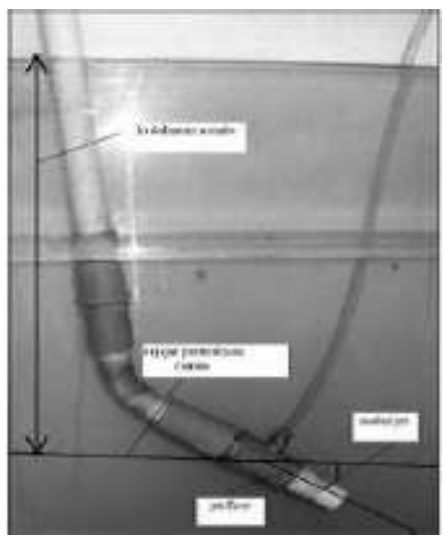

Gambar 6. Prosedur pengukuran sudut dan kedalaman nosel tercelup

Untuk pengujian kemampuan absorpsi $\mathrm{CO}_{2}$ terhadap 82 jenis konfigurasi, dilakukan seleksi dengan uji hidrodinamika berdasarkan parameter gas entrainment dan hold-up fasa gas untuk menentukan konfigurasi terpilih. Gas entrainment diukur dengan mengambil data sampel gas yang terhisap masuk ke dalam cairan kolom. Sedangkan hold-up fasa gas adalah fraksi fasa gas dalam kolom, diukur berdasarkan laju alir gas entrainment serta laju cairan.

Uji absorpsi $\mathrm{CO}_{2}$ dilakukan dengan menggunakan konsentrasi gas $\mathrm{CO}_{2}$ awal 
sebesar 96,60\% dan laju alir $\mathrm{CO}_{2}$ sebesar 5 L/min. Parameter absorpsi yang diukur adalah waktu absorpsi, diukur berdasarkan perubahan warna absorben $\mathrm{NaOH} \mathrm{0,01} \mathrm{M} \mathrm{dari}$ ungu menjadi bening dengan menggunakan indikator phenolptalein. Perubahan warna absorben tersebut menandakan absorben $\mathrm{NaOH}$ habis bereaksi dengan gas $\mathrm{CO}_{2}$ dan sebagai patokan waktu absorpsi.

Untuk mengukur populasi gelembung, dilakukan pengambilan foto gelembung dalam kolom flat. Berdasarkan data foto tersebut, diukur diameter berbagai gelembung melalui layar komputer dengan menggunakan standar diameter pipa tercelup yang telah diketahui ukurannya. Dilakukan perhitungan persentase distribusi jumlah gelembung berdasarkan jumlah gelembung pada rentang diameter tertentu terhadap populasi diameter gelembung keseluruhan yang terukur.

\section{Hasil dan Pembahasan Pemilihan konfigurasi}

Pemilihan konfigurasi terbaik berdasarkan gas entrainment rate dan hold-up fasa gas yang setinggi-tingginya. Gambar 7 memperlihatkan hasil pengujian hidrodinamika dari 82 jenis konfigurasi dimana hasil pengukuran hold-up fasa gas $\left(\varepsilon_{\mathrm{G}}\right)$ meningkat secara parabolik terhadap kenaikkan rasio laju alir gas terhadap laju alir cairan $\left(\mathrm{Q}_{\mathrm{G}} / \mathrm{Q}_{\mathrm{L}}\right)$. Dari gambar terlihat bahwa dari konfigurasi yang diujikan setidaknya ada 5 konfigurasi terbaik dengan nilai $\varepsilon_{\mathrm{G}}$ antara 0,6-0,7 dan rasio $Q_{G} / Q_{L}$ berkisar di atas 2 . Ternyata ada harga $\varepsilon_{\mathrm{G}}$ dan $\mathrm{Q}_{\mathrm{G}} / \mathrm{Q}_{\mathrm{L}}$ dibawah 0,3 dan 0,4. Ini menandakan bahwa desain konfigurasi liquid jet dari hasil penempatan nosel memberikan pengaruh yang signifikan terhadap sistem kontak gas-cair. Berdasarkan data hasil uji hidrodinamika diperoleh 5 jenis konfigurasi terbaik (Tabel 1) dari 82 jenis konfigurasi. Posisi nosel kelima jenis konfigurasi tersebut ternyata berada di sekitar permukaaan air dengan kedalaman maksimal sekitar 2,3 cm serta sudut tembakan dengan kemiringan arah kebawah 40-70. Dan ternyata hold-up gas dan rasio gas di bawah 0,3 dan 0,4 dihasilkan dari konfigurasi dengan posisi nosel dibawah permukaan air. Hasil ini memperlihatkan bahwa konfigurasi kolom gelembung dengan menggunakan jet flow dengan posisi nosel dibawah permukaan cairan mempunyai kemampuan kinerja yang lebih baik dalam kontak gas dan cair dibandingkan dengan penempatan nosel di atas permukaan air.

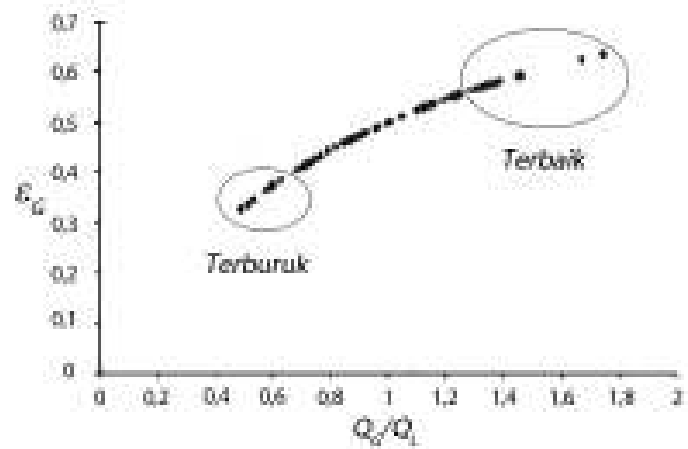

Gambar 7. Pemilihan konfigurasi berdasarkan gas entrainment \& hold-up gas.

\begin{tabular}{ccccc}
\multicolumn{5}{c}{$\begin{array}{c}\text { Tabel 1. Konfigurasi Terpilih Hasil Uji } \\
\text { Hidrodinamika dan Absorpsi }\end{array}$} \\
\hline $\begin{array}{c}\text { Sudut } \\
\text { (der) }\end{array}$ & $\begin{array}{c}\text { Posisi } \\
\text { Nosel } \\
\text { (cm) }\end{array}$ & QG/QL & $\boldsymbol{E}_{\mathbf{G}}$ & $\begin{array}{c}\text { Waktu } \\
\text { absorbsi } \\
\text { (detik) }\end{array}$ \\
\hline-60 & $-2,3$ & 2,47 & 0,71 & 15,84 \\
-40 & $-2,2$ & 2,00 & 0,67 & 17,03 \\
-70 & $-2,6$ & 2,02 & 0,67 & 18,62 \\
-55 & $-1,6$ & 2,22 & 0,69 & 20,87 \\
-80 & 0,7 & 1,94 & 0,66 & 21,62 \\
25 & 48,6 & 0,40 & 0,29 & 25,88 \\
35 & 46,2 & 0,40 & 0,29 & 28,66 \\
30 & 58,1 & 0,14 & 0,12 & 35,03 \\
20 & 49,6 & 0,39 & 0,28 & 24,34 \\
60 & 41,3 & 0,26 & 0,21 & 29,82 \\
\hline
\end{tabular}

\section{Uji absorpsi $\mathrm{CO}_{2}$}

Uji absorpsi terhadap konfigurasi terpilih dari hasil uji hidrodinamika hasilnya dapat dilihat Tabel 1 (kolom 5). Uji absorpsi digunakan konsentrasi $\mathrm{CO}_{2}$ awal sebesar 96,60\% dan laju alir $\mathrm{CO}_{2}$ sebesar $5 \mathrm{~L} / \mathrm{min}$. Pengukuran waktu absorpsi ditandai dengan perubahan warna dari ungu menjadi bening akibat dengan menggunakan indikator phenolptalein (pp). Perubahan warna absorben tersebut menandakan waktu absorpsi saat absorben $\mathrm{NaOH}$ telah habis bereaksi. Seperti nampak pada tabel bahwa hasil uji hidrodinamika sejalan dengan hasil uji absorpsi $\mathrm{CO}_{2}$. Konfigurasi dengan nilai $\varepsilon_{\mathrm{G}}$ di atas 0,6 dan rasio $\mathrm{Q}_{\mathrm{G}} / \mathrm{Q}_{\mathrm{L}} \mathrm{di}$ atas 2 menghasilkan absorpsi $\mathrm{CO}_{2}$ dengan waktu yang lebih cepat (dibawah 20 detik) dibandingkan dengan konfigurasi rentang $\varepsilon_{\mathrm{G}}$ dan $Q_{G} / Q_{L}$ yang rendah (dibawah 0,3 dan 0,4). Oleh karenanya dapat disimpulkan bahwa adanya pengaruh yang signifikan konfigurasi jet flow kolom gelembung terhadap parameter hidrodinamika $\left(\varepsilon_{\mathrm{G}}, \mathrm{Q}_{\mathrm{G}} / \mathrm{Q}_{\mathrm{L}}\right)$ dan laju absorpsi.

\section{Absorpsi kimiawi}


Uji kemampuan absorpsi gas $\mathrm{CO}_{2}$ menggunakan $\mathrm{NaOH} 1 \%$ disajikan pada Gambar 8. Konsentrasi awal $\mathrm{CO}_{2}$ sebesar $96,60 \%$ dapat diturunkan menjadi $\sim 0 \%$ dalam waktu 3 menit pertama. Pada rentang waktu berikutnya (menit ke-6 dan ke-9) ternyata tidak menunjukkan kenaikan konsentrasi $\mathrm{CO}_{2}$ dan konsentrasi $\mathrm{CO}_{2}$ dalam gas tetap $\sim 0 \%$. Hal ini menandakan tidak terjadinya proses desorpsi atau absorpsi balik $\mathrm{CO}_{2}$ menuju fasa gas. Ikatan yang terjadi antara absorben $\mathrm{NaOH}$ dengan gas $\mathrm{CO}_{2}$ dapat dipastikan berupa ikatan kimiawi yang kuat. Komponen gas $\mathrm{CO}_{2}$ tidak terlepas kembali ke fasa gas walaupun cairan absorben terkena putaran propeller pompa yang memberikan energi kinetik pada cairan asorben $\mathrm{NaOH}$ untuk dapat melepaskan kembali $\mathrm{CO}_{2}$ yang telah diikatnya.

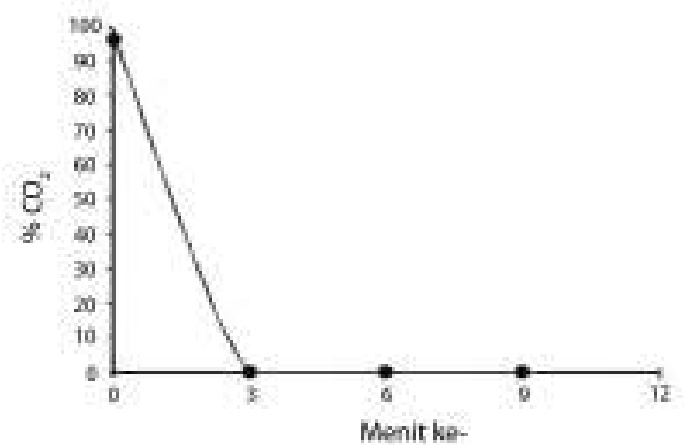

Gambar 8. Kurva penurunan konsentrasi $\mathrm{CO}_{2}$ dalam rentang waktu panjang

\section{Distribusi gelembung}

Aspek distrbusi gelembung cukup penting diukur, karena efektivitas kontak gascair dari proses absorpsi juga ditentukan oleh populasi gelembung yang terbentuk di dalam cairan. Pada prinsipnya, kontak fasa gas-cair yang ideal apabila diameter gelembung yang terbentuk seminimal mungkin dengan jumlah dan dispersi gelembung yang semaksimal mungkin. Gambar 9 merupakan hasil pengukuran populasi gelem-bung dalam rentang diameter untuk tiga konfigurasi terbaik dan terburuk berdasarkan uji absorpsi $\mathrm{CO}_{2}$.

Terlihat jelas bahwa pola kurva untuk tiga konfigurasi terbaik, populasi gelembung yang lebih dominan adalah gelembung dengan rentang diameter yang lebih kecil yaitu 0,00097-0,00184 mm. Berbeda dengan tiga konfigurasi kurang baik (hold up gas dan rasio gas rendah) pola kurva mengarah pada populasi gelembung dengan rentang diameter yang lebih besar yaitu 0,00625-0,00712 mm. Berdasarkan hasil ini, jelaslah bahwa konfigurasi dengan gas hold-up dan rasio $\mathrm{Q}_{\mathrm{G}} / \mathrm{Q}_{\mathrm{L}}$ yang tinggi menghasilkan populasi awan gelembung dengan diameter yang sekecil-kecilnya dan jumlah yang sebesarbesarnya. Sistem kontak gas-cair dengan terbentuknya awan gelembung tersebut sangat efektif untuk melangsungkan proses absorpsi $\mathrm{CO}_{2}$. Karena proses absorpsi melibatkan proses perpindahan massa dengan memerlukan luas kontak yang setinggitingginya yang diciptakan oleh gelembung yang terbentuk tersebut.

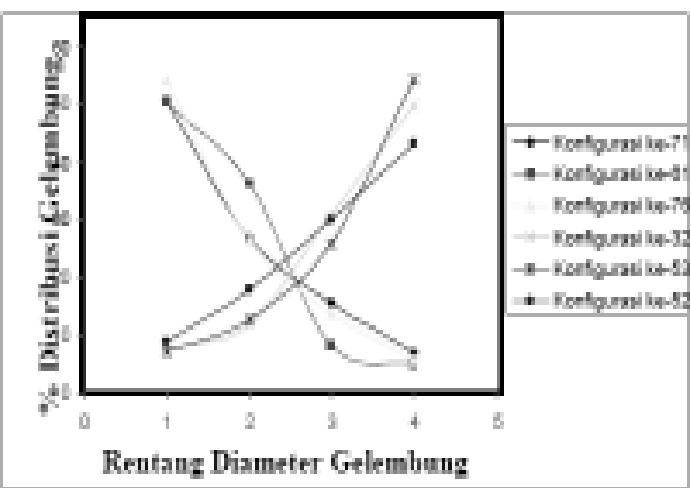

Gambar 9. Distribusi rentang diameter gelembung

\section{Kesimpulan}

Desain konfigurasi jet flow kolom gelembung memberikan pengaruh yang signifikan terhadap hasil parameter hidrodinamika $\left(\varepsilon_{\mathrm{G}}, \mathrm{Q}_{\mathrm{G}} / \mathrm{Q}_{\mathrm{L}}\right)$, laju absorpsi serta populasi terbentuknya gelembung di dalam cairan. Didapatkan bahwa posisi nosel untuk konfigurasi yang baik ternyata berada di sekitar permukaaan air dengan kedalaman maksimal sekitar 2,3 cm serta sudut tembakan arah kebawah dengan antara 40$70^{\circ}$. Konfigurasi dengan didapatkan nilai $\varepsilon_{\mathrm{G}}$ di atas 0,6 dan rasio $\mathrm{Q}_{\mathrm{G}} / \mathrm{Q}_{\mathrm{L}}$ di atas 2 menghasilkan absorpsi $\mathrm{CO}_{2}$ dengan waktu yang lebih cepat (di bawah 20 detik). Ikatan yang terjadi antara absorben $\mathrm{NaOH}$ dengan gas $\mathrm{CO}_{2}$ dapat dipastikan berupa ikatan kimiawi. Desain konfigurasi dengan gas holdup dan rasio $\mathrm{Q}_{\mathrm{G}} / \mathrm{Q}_{\mathrm{L}}$ yang tinggi menghasilkan populasi awan gelembung dengan diameter yang sekecil-kecilnya.

\section{Ucapan Terima Kasih}

Penulis mengucapkan banyak terima kasih kepada segala pihak yang telah ikut terlaksananya kelancaran penelitian ini, terutama laboratorium Kimia Fisika, Teknik 
Kimia-UI. Serta pihak DP2M-DIKTI telah memberikan dukungan dana dalam bentuk Penelitian Hibah Bersaing XVI (2008-2009)

\section{Daftar Notasi}

$\varepsilon_{\mathrm{G}}=$ Hold-up fasa gas

$Q_{G}=$ Laju alir volumetrik gas (L/min)

$Q_{L}=$ Laju alir volumetrik cairan $(\mathrm{L} / \mathrm{min})$

\section{Daftar Pustaka}

Akira, I.; Yamagiwa, K.; Tajima, K.; Yoshida, M.; Ohkawa, A., Maximum Penetration Depth of Air Bubbles Entrained by Vertical Liquid Jet, Journal of Chemical Engineering of Japan, 2000, Vol. 33(6), 898-900.

Evans, G. M., A Study Of A Plunging Jet Bubble Column, Doctor Thesis, The University of Newcastle, Australia, 1990.

Ide, M.; Uchiyama, H.; Ishikura, T., Mass transfer characteristics in gas bubble dispersed phase generated by plunging jet containing small solute bubbles, Chemical Engineering Science, 2001, Vol. 56(21-22), 6225-6231.

Lee, S. Y.; Tsui, P., Succeed at Gas/Liquid Contacting, Chemical Engineering Progress, 1998, Vol. 95(7), 23-49.

Liu, G.; Evans, G. M., Gas Entrainment and Gas Hold up in a Confined Plunging Liquid Jet Reactor, Proceedings of the 26th Australasian Chemical Engineering Conference 1998, E1, Port Douglas, Australia, 1998.

Rabindran, Gas-Liquid Reactor, http://www.Chemsoc.org/exemplarchem/ent ries/2001 (akses November 2007).

Yamagiwa, K.; Kusabiraki, D.; Gas holdup and gas entrainment rate in downflow bubble column with gas entrainment by a liquid jet operating at high liquid throughput, Journal of Chemical Engineering Japan, 1990, Vol. 23(3), 343-348. 